\title{
OFICINAS PEDAGÓGICAS DE CIÊNCIAS: OS MOVIMENTOS PEDAGÓGICOS PREDOMINANTES NA FORMAÇÃO CONTINUADA DE PROFESSORES
}

\author{
Pedagogical Sciences workshops: influential \\ pedagogical movements in teachers' training
}

\author{
Lucia Helena Pralon de Souza ${ }^{1}$ \\ Guaracira Gouvêa ${ }^{2}$
}

Resumo: Nas últimas décadas os professores têm convivido com o discurso constante da necessidade de atualização permanente. Muitos estudos e pesquisas acadêmicas confirmam essa real necessidade. Nos grandes centros urbanos brasileiros não faltam oportunidades para cursos, mini-cursos e oficinas oferecidos pelos inúmeros espaços que atuam na formação continuada de professores. Neste trabalho apresenta-se parte de estudo sobre as Oficinas Pedagógicas de Ciências oferecidas para a formação continuada de professores no Rio de Janeiro nos últimos dez anos, recurso que tem desempenhado significativo papel na progressão profissional dos professores. Utilizando referenciais teóricos da Filosofia, da linguagem e da formação do professor de Ciências foram analisados títulos e ementas de 175 oficinas, textos que representam categoria particular de diálogo entre as instituições (pesquisa), os professores (escola) e a sociedade. O objetivo foi identificar as vozes que se fazem presentes e revelam os movimentos pedagógicos mais influentes no período em questão.

Palavras-chave: oficinas pedagógicas. formação continuada. ensino de Ciências.

\begin{abstract}
Teachers have been living with an insistent discourse about their continuing development over the last decades. A great number of studies and researches reinforce this as a real necessity. In the great Brazilian urban centers teachers have many development opportunities in brief or long courses and workshops, offered by the training teacher establishments. In this work we present part of a study on Pedagogical Science Workshops offered in Rio de Janeiro, to teachers in training for the last ten years, considering this an important role in teachers' professional development. Based on the philosophy of language and references to science teachers theoretical development we have analyzed the titles and descriptions of 175 science workshops, believing that these texts represent a particular dialogue category among institution (researches), teachers (school) and society. Thus we wish to identify the present voices that show us the most influential pedagogical movements throughout the period.
\end{abstract}

Keywords: work shop. teacher training. Science education.

\footnotetext{
${ }^{1}$ Professora, Rede Municipal de Educação do Rio de Janeiro; Professora, curso de Pedagogia para os anos iniciais do Ensino Fundamental, Universidade Federal do Estado do Rio de Janeiro (PAIEF/UNIRIO/CEDERJ).

E-mail:luciapralon2@yahoo.com.br

${ }^{2}$ Professora, Núcleo de Tecnologia Educacional para a Saúde, Universidade Federal do Rio de Janeiro (NUTES/UFRJ);

Professora, UNIRIO.E-mail:guaracirag@uol.com.br
} 
Souza, L. H. P.; Gouvêa, G.

\title{
Introdução
}

É muito difícil para qualquer professor sentir-se seguro e suficientemente competente perante o insistente discurso, proferido por diferentes segmentos sociais, sobre sua má formação inicial e a necessidade de atualização permanente. Muitos estudos e pesquisas acadêmicas (Krasilchik, 1987; Marandino, 1994; Porlán e Rivero, 1998; Christov, 1998; Copello Levy e Sanmartí Puig 2001; Pimenta, 1999; Selles, 2000; Viana e Carvalho, 2000; Amaral, 2003) têm confirmado a real necessidade de uma permanente atualização dos profissionais da educação.

\begin{abstract}
A Educação Continuada se faz necessária pela própria natureza do saber e do fazer humanos como práticas que se transformam constantemente. A realidade muda e o saber que construimos sobre ela precisa ser revisto e ampliado sempre. Dessa forma, um programa de educação continuada se faz necessário para atualizarmos nossos conhecimentos, principalmente para analisarmos as mudanças que ocorrem em nossa prática, bem como para atribuirmos direções esperadas a essas mudanças. (Christov, 1998, p. 9)
\end{abstract}

A necessidade de uma formação permanente dos professores também fica clara quando se reflete sobre as limitações da formação inicial. Segundo Gil-Pérez (2003), os países que possuem um sistema educativo mais avançado tendem a investir mais na formação permanente que na formação inicial devido a três fatores: 1) muitos dos problemas que devem ser tratados não adquirem sentido até que o professor se depare com eles em sua própria prática; 2) as exigências de formação são tão grandes que tentar cobri-las no período inicial conduziria ou a uma duração absurda, ou a um tratamento absolutamente superficial; 3) uma formação docente realmente efetiva supõe a participação continuada em equipes de trabalho e em tarefas de pesquisa/ação que, é óbvio, não podem ser realizadas, com um mínimo de profundidade, durante a formação inicial (Stenhouse, 1975; Gil-Pérez, 1982).

Nos grandes centros urbanos brasileiros, como é o caso da cidade do Rio de Janeiro, não faltam oportunidades para o professor se atualizar. São muitos os espaços que atuam na formação continuada de professores de Ciências, oferecendo as mais variadas possibilidades de atualização em cursos, mini-cursos e oficinas, com diferentes cargas horárias.

Questões referentes à carga horária das propostas de atualização e a seu conteúdo costumam ser alvo de debates calorosos entre os formadores. Parece óbvio que os cursos mais longos devem apresentar resultado mais eficiente na aprendizagem do professor que uma oficina de apenas quatro horas. No entanto, é preciso considerar que este tipo de encontro de curta duração tem sido oferecido com bastante freqüência em muitos espaços de formação continuada e tem contado com uma participação muito representativa de professores.

Deve-se levar em conta que muitas vezes o professor não tem disponibilidade de tempo e/ou recursos para freqüentar cursos de atualização. Neste estudo, pôde-se identificar pelo menos dois fatores que dificultam a adesão a cursos mais longos: os baixos salários, em decorrência de um processo histórico de desvalorização do profissional da educação, que obriga o professor à dupla ou tripla jornada de trabalho e praticamente inviabiliza sua participação, e o acúmulo de funções, haja visto que a grande maioria dos professores (principalmente no Ensino Fundamental) é composta por mulheres que, além da jornada profissional diária, 
acumulam a maior parte das tarefas domésticas, dos cuidados com a casa à saúde e educação dos filhos.

Desta forma, as oficinas podem contribuir para a formação dos professores, pois são atividades pontuais de curta duração que, a longo prazo, agem como espaços de formação contínua, na medida em que um dia o professor participa de um encontro, em um outro dia vai a outro, ou seja, há uma continuidade construída por sua própria demanda.

Com base nesses argumentos percebeu-se a relevância de uma investigação sobre Oficinas Pedagógicas. Neste trabalho apresentam-se os resultados parciais da análise de 175 propostas de Oficinas Pedagógicas de Ciências oferecidas durante o período de 1992 a 2002 por quatro instituições sediadas na cidade do Rio de Janeiro.

\section{O caminho metodológico}

Para realizar a investigação proposta surgiu uma dificuldade metodológica inicial: a impossibilidade de coletar dados a partir de contato direto com os idealizadores das oficinas no momento da sua concepção e realização. Como resgatar o contexto sociocultural no qual esses encontros foram idealizados e realizados? Afinal, por se tratar de uma investigação que remete a outro tempo, ao passado, mesmo que houvesse a intenção de entrevistar pessoalmente cada autor de oficina, hoje sua fala seria diferente da do momento em que a Oficina foi elaborada. O caminho alternativo foi proceder à análise de seus registros - títulos e ementas estes, sim, possíveis de serem resgatados em folders, atas e resumos de encontros e congressos e/ou nos arquivos das instituições pesquisadas.

Para delimitar o universo da pesquisa, o procedimento incluiu a identificação das principais instituições envolvidas com formação continuada de professores de Ciências no estado do Rio de Janeiro, seleção e caracterização das instituições participantes da pesquisa e definição do recorte temporal no qual se concentraria a coleta de dados. Estas escolhas justificam-se pelo fato de que mapear todas as instituições brasileiras que adotam a metodologia de oficinas na formação continuada de professores de Ciências e coletar material ao longo de um período de tempo muito extenso seria tarefa penosa e quase impossível. A investida limitou-se aos últimos dez anos e no âmbito de apenas quatro instituições: CECIERJ ${ }^{3}$, mediante seu projeto Praça da Ciência Itinerante, Projeto Fundão Biologia - UFRJ, Espaço UFF de Ciências, com o Projeto "Uma andorinha só não faz verão" e Secretaria Municipal de Educação do Rio de Janeiro, Projeto dos Pólos de Ciências e Matemática.

${ }^{3}$ O CECIERJ é um Centro de Ciências ligado ao governo do Estado que tem suas origens no antigo CECIGUA - Centro de Ciências da Guanabara, fundado em 1965 e que, a partir da fusão dos Estados da Guanabara e do Rio de Janeiro, em 1974, passou a ser chamado de CECI - Centro de Ciências. No governo Moreira Franco (19861990) o CECI foi transformado em autarquia e passou a fazer parte da Secretaria de Ciência e Tecnologia do Estado passando, então, a ser denominado CECIERJ. 
O projeto Praça da Ciência Itinerante surgiu em 1995 e é coordenado pela Fundação Centro de Ciências e Educação Superior à Distância do Estado do Rio de janeiro, (Fundação CECIERJ/ Consórcio CEDERJ). Apresenta três linhas de ação: atendimento aos alunos no seu espaço escolar, atualização de professores e Praça da Ciência Itinerante. A primeira linha se desenvolve pelo atendimento às escolas públicas dos municípios do estado do Rio de Janeiro, oferecendo diversas atividades ao longo de dois dias seguidos. A atualização de professores, segunda linha de ação, contempla oficinas dirigidas ao corpo docente das escolas atendidas. A terceira linha prevê atividades realizadas em local aberto e destinadas a professores, alunos, funcionários e comunidades próximas às escolas. Este projeto congrega várias outras instituições e centros de produção do saber na apresentação de suas atividades como, por exemplo, a Faculdade de Arquitetura e Urbanismo da UFRJ, o Espaço Ciência Viva, o Espaço UFF de Ciências e o Museu de Astronomia e Ciências Afins.

Com objetivo de contribuir para a melhoria do ensino em 1983 teve início o projeto Fundão - Desafio para a Universidade - UFRJ (PADCT - SPEC - CAPES), que oferecia espaço de formação permanente aos professores dos ensinos Fundamental e Médio, a partir da iniciativa de professores da universidade de reunir projetos que vinham desenvolvendo ações nesse sentido nas diversas áreas. Inicialmente englobando os setores da Biologia, Geografia, Física, Matemática e Química, hoje o projeto conta com apenas dois setores atuantes: Matemática e Biologia. O Projeto Fundão Biologia foi inicialmente assumido por professores e licenciandos do Instituto de Biologia da UFRJ e, mais tarde, integraram-se à equipe professores das redes pública e particular de ensino, que passaram a atuar como professores multiplicadores, ou seja, atuavam junto a outros professores colaborando com sua formação.

A partir de uma iniciativa da Universidade Federal Fluminense, o projeto Uma andorinha só não faz verão foi iniciado em 1995 e manteve suas atividades até o início de 2000. Desenvolvido no Espaço-UFF de Ciências ${ }^{4}$, e com objetivo de promover maior intercâmbio com as escolas de Ensino Fundamental, este projeto atuou em cinco regiões do Rio de Janeiro (Município do Rio de Janeiro, São João de Meriti, Baixada Fluminense, Niterói e Maricá). Sua metodologia de trabalho compreendia encontros com duração de um dia, no qual debates teóricos sobre questões emergentes no cenário educacional eram seguidos de Oficinas Pedagógicas e finalizados com uma mesa-redonda de avaliação dos trabalhos. Uma característica marcante do projeto foi o envolvimento direto de professores da região e da escola escolhida para sediar o encontro na tarefa de organização do mesmo. Além disso, muitas oficinas eram ministradas por professores, também chamados de multiplicadores, que apresentavam suas experiências docentes como subsídios aos colegas.

Os Pólos de Ciências e Matemática, criados em 1996 e coordenados pelo Projeto Ciências e Matemática da Secretaria Municipal de Educação do Rio de Janeiro, desenvolviam trabalho de formação continuada de ação regional, procurando atender às necessidades locais dos professores das Coordenadorias Regionais de Educação (E-CRE) daquela secretaria. Na pro-

${ }^{4}$ O Espaço UFF de Ciências, fundado em 1991, é um programa de extensão da Universidade Federal Fluminense, vinculado ao ensino e à pesquisa e voltado para a difusão das Ciências, de sua história e seu ensino. 
posta original, cada CRE contaria com um Pólo, sediado em uma das escolas da região e com uma equipe de professores com a seguinte constituição preferencial: um professor de Matemática, um professor de Ciências e um professor das séries iniciais do Ensino Fundamental. Estes professores, selecionados na própria rede de acordo com critérios adotados pela instituição para definir o perfil profissional, já atuando nos Pólos dedicavam parte de sua carga horária para a própria atualização.

A escolha dessas quatro instituições justifica-se, principalmente, por duas razões: em primeiro lugar pelo fato de já existirem estudos sobre algumas delas (Krasilchik, 1987; Marandino, 1994), nos quais os movimentos pedagógicos que mais influenciaram suas ações até o início dos anos 1990 foram identificados; em segundo lugar, pela sua efetiva ação na formação continuada de professores utilizando o recurso oficina de forma contínua e dentro do período analisado.

Os dados coletados nas instituições perfazem um total de informações sobre 175 Oficinas Pedagógicas de Ciências, sendo: 35 do projeto Fundão Biologia/UFRJ; 16 do projeto Uma andorinha só não faz verão/UFF; 24 do projeto Praça da Ciência Itinerante/CECIERJ e cem dos Pólos de Ciências e Matemática/SME-RJ.

\section{A análise dos dados}

Segundo Minayo (2000), um grande obstáculo encontrado pelos pesquisadores no momento da análise dos dados recolhidos é a, chamada por Bourdieu, "ilusão de transparência". Trata-se do

perigo de uma compreensão espontânea como se o real se mostrasse nitidamente ao observador. Essa "ilusão" é tanto mais perigosa, quanto mais o pesquisador tenha a impressão de familiaridade com o objeto. Trata-se de uma luta contra a sociologia ingênua e o empirismo, que acreditam poder apreender as significações dos atores sociais mas apenas conseguem a projeção de sua própria subjetividade. (p. 197)

Cientes desse risco, que decorre da inserção dos autores deste estudo em algumas das instituições pesquisadas e conseqüente familiaridade com o objeto de pesquisa, a primeira aproximação aos dados deu-se mediante exaustivo contato de leitura, manuseio e tentativas de categorização, ainda sem o compromisso de uma fundamentação teórica, mais com o objetivo de permitir uma impregnação de seu conteúdo. Sempre resgatando os objetivos do trabalho, buscou-se, pela "leitura flutuante" (Minayo, 2000, p. 209), perceber nos discursos escritos algum sentido que pudesse dar partida ao processo de análise.

\footnotetext{
${ }^{5}$ Neste trabalho usamos o termo movimentos pedagógicos com o significado adotado por Nóvoa (1999 p. 15-16), "colectivos de professores que se organizam em torno de princípios educativos ou de propostas de acção, da difusão de métodos de ensino ou da defesa de determinados ideais".
} 
Das várias possibilidades de análise encontradas e exploradas descreve-se, aqui, o que chamou-se de "terceiro olhar sobre os dados". Nesta etapa, refletiu-se sobre as diferentes vozes que se fazem ouvir pelos enunciados polifônicos (os títulos e as ementas das oficinas analisadas) e que revelam os movimentos pedagógicos ${ }^{5}$ predominantes no ensino de Ciências na década analisada.

O posicionamento em relação a uma concepção de linguagem e a adoção de uma postura de análise do texto escrito foram apoiados na teoria da linguagem e do dialogismo de Mikhail Bakhtin, que concebe uma complexidade nas manifestações de linguagem em situações sociais concretas. Para Bakhtin (1986) a palavra na boca do locutor assume mais que seu papel de sinal, ou seja, de palavra com significado duro, estável, sempre igual a si mesma, descontextualizada. Ela é signo, pois traz consigo uma significação particular que deve ser compreendida num contexto concreto, preciso para cada enunciação.

O dialogismo é o princípio constitutivo da linguagem e a condição do sentido do discurso. Para Bakhtin, ignorar a natureza dialógica da linguagem é o mesmo que apagar a ligação que existe entre a linguagem e a vida. A dialogia diz respeito às diversas maneiras como duas ou mais vozes entram em contato em um discurso. Bakhtin (1986) considera que o discurso nunca é individual, na medida em que se constrói entre pelo menos dois interlocutores que, por sua vez, são seres sociais e, ainda, porque é construído como um diálogo entre discursos. Para reafirmar o caráter dialógico do discurso, Bakhtin propõe que sua unidade de análise seja a enunciação.

A enunciação é o resultado da interação entre indivíduos na sociedade. Para que se compreenda uma enunciação é preciso entender sua relação com outras enunciações. Em uma enunciação as palavras carregam uma história de enunciações anteriores: elas não foram criadas naquele momento, já foram proferidas em situações anteriores e, por alguma razão, foram acolhidas pelo locutor. Ao incorporar uma palavra em seu discurso, o enunciador atribui crédito à palavra do outro, acolhendo, investigando seu sentido, concordando ou discordando em maior ou menor grau, ultrapassando os limites da compreensão imediata.

Os discursos dos títulos e ementas das oficinas são enunciações polifônicas e, como tal, permitem ver os diálogos travados entre diferentes discursos, entre diferentes vozes. Acredita-se que algumas palavras encontradas nesses textos são representações ou pistas das vozes presentes. Para Bakhtin (1986) a palavra é onisignificante, ou seja, guarda uma multiplicidade de significações que têm seu sentido atrelado à situação concreta em que cada enunciação se realiza. Assim,

a investigação da significação de um ou outro elemento lingüistico pode (...) orientar-se para duas direçôes: para o estágio superior, o tema; nesse caso, tratar-se-ia da investigação da significação contextual de uma dada palavra nas condições de uma enunciação concreta. Ou então ela pode tender para o estágio inferior, o da significação: nesse caso, será a investigação da significação da palavra no sistema da lingua ou, em outros termos, a investigação da palavra dicionarizada. (Bakhtin, 1986, p. 131)

Desse modo, algumas palavras recorrentes nos títulos e ementas das oficinas analisadas - como, por exemplo: cidadão, crítico, reflexivo, interdisciplinar, concepções (prévias), construção (de conhecimento), cotidiano, sucata, materiais de baixo custo, lúdico, atividade 
Oficinas pedagógicas de Ciências: os movimentos...

prática, experimentação, reciclagem, reutilização e modelos - remetem a temas, a determinados movimentos pedagógicos, a referenciais teóricos, a demandas sociais, a demandas da práxis do professor etc. Trata-se do discurso do outro sendo usado na estruturação de um novo discurso, de um diálogo entre discursos.

Com o objetivo de identificar esses diálogos, procedeu-se a um exame dos textos dos títulos e ementas das oficinas pedagógicas pesquisadas, no qual encontraram-se palavras e expressões que, no contexto da enunciação, remetiam a algum movimento pedagógico, a um tipo particular de discurso.

Exemplo: Oficina: PF-33

Titulo: Vendo com outros olhos: resignificando os conceitos de tempo e espaço.

Ementa: Alternativas metodológicas para auxiliar os alunos na construção dos conceitos de grandes dimensões cósmicas e dimensões microscópicas, abordadas no ensino de ciências.

Neste exemplo, as palavras destacadas em negrito remetem ao movimento do construtivismo e das mudanças conceituais. A opção por esses termos e não por outros está fortemente ligada ao contexto de produção, ao momento histórico e social, com todas as influências decorrentes, e somente nele tem sentido. Em outro momento histórico, sob outras influências teóricas, as palavras certamente seriam outras. Sem o contexto daquele referencial teórico, o locutor poderia ter estruturado seu texto com outras palavras como, compreendendo no titulo, ou compreensão - na ementa, e a enunciação assumiria outro sentido.

Outros termos encontrados remetem aos mais diferentes movimentos pedagógicos, como se pode ver a seguir:

Exemplo: Oficina: CE-23

Titulo: Construção de "kits" para ensino de Ciências sob a ótica da educação ambiental Ementa: Estamos apresentando nesta oficina, de forma simples, prática e criativa, a construção de jogos, brinquedos (kits) para ensino de Ciências, através de materiais simples e de baixo custo (sucata). Por acreditarmos que brinquedo é um objeto facilitador do desenvolvimento das atividades lúdicas, que desperta a curiosidade, exercita a inteligência, permite a invenção e a imaginação, é que estamos apresentando nesta oficina algumas idéias que julgamos fundamentais para...

O termo Construção de "kits" tem a ver com o movimento do ensino experimental que trouxe o aluno para o centro do processo de ensino-aprendizagem, na medida em que postulava a necessidade de vivenciar o fenômeno para possibilitar a aprendizagem, quer por atividades experimentais individualizadas quer por meio de demonstrações coletivas. Pode-se considerar que a expressão materiais simples e de baixo custo remete a um movimento que tem suas origens nas tendências tecnicistas dos anos 1960, que criaram uma demanda, por parte dos professores, de viabilizar atividades práticas dificilmente realizáveis porque muitas das escolas não eram devidamente equipadas para a realização de atividades experimentais. $O$ terceiro termo negritado, atividades lúdicas, tem relação com a tendência pedagógica de tornar o processo de ensino-aprendizagem algo prazeroso e significativo para os alunos. Não 
se pode negar que as atividades lúdicas afetam de forma benéfica alguns aspectos ligados à aprendizagem, como a socialização, afeição, motivação e criatividade.

Os exemplos citados servem para ilustrar o modo como os diferentes discursos pedagógicos no interior dos enunciados foram percebidos e identificados. A Tabela 1 é uma síntese dos temas ou, como preferiu-se chamar, dos movimentos pedagógicos que pudemos localizar nos títulos e ementas, sua recorrência em cada instituição individualmente e, na última coluna, o número total de ocorrências em nosso universo de dados.

Tabela 1. Movimentos pedagógicos localizados nos títulos e ementas.

\begin{tabular}{|c|c|c|c|c|c|}
\hline Movimentos pedagógicos & $\begin{array}{c}\text { PCM } \\
\text { (em } 100 \\
\text { oficinas) }\end{array}$ & $\begin{array}{c}\text { PF } \\
\text { (em } 35 \\
\text { oficinas) }\end{array}$ & $\begin{array}{c}\text { UFF } \\
\text { (em } 16 \\
\text { oficinas) }\end{array}$ & $\begin{array}{c}\text { CE } \\
\text { (em } 24 \\
\text { oficinas) }\end{array}$ & $\begin{array}{c}\text { TOTAL } \\
\text { (em } 175 \\
\text { oficinas) }\end{array}$ \\
\hline ensino experimental & 10 & 10 & - & 5 & 25 \\
\hline ensino lúdico & 7 & 9 & 4 & 5 & 25 \\
\hline interdisciplinaridade & 12 & 4 & 1 & 6 & 23 \\
\hline educação ambiental & 18 & 2 & - & 1 & 21 \\
\hline construtivismo & 8 & 1 & - & 2 & 11 \\
\hline trabalho com materiais de baixo custo, sucata & 2 & 3 & - & 5 & 10 \\
\hline ensino significativo (cotidiano) & 4 & 4 & - & 1 & 9 \\
\hline modelos pedagógicos & 5 & 2 & 1 & 1 & 9 \\
\hline filosofia da libertação (educação para cidadania) & 7 & - & - & - & 7 \\
\hline atividade prática para sala de aula & 6 & 1 & - & - & 7 \\
\hline mudança conceitual & 3 & 3 & - & - & 6 \\
\hline PCN's & 3 & 1 & 1 & 1 & 6 \\
\hline ensino crítico & 5 & 1 & - & - & 6 \\
\hline Não dicotomia teoria/prática & 2 & 3 & - & - & 5 \\
\hline pré-concepções & 3 & - & - & - & 3 \\
\hline uso de material concreto & 2 & - & 1 & - & 3 \\
\hline reforça a dicotomia teoria/prática & - & - & - & 2 & 2 \\
\hline diagnose ambiental (Rio 92) & 2 & - & - & - & 2 \\
\hline professor como transmissor & - & - & - & 2 & 2 \\
\hline necessidade de formação continuada & 2 & - & - & - & 2 \\
\hline professor reflexivo & 1 & - & - & - & 1 \\
\hline professor como mediador & 1 & - & - & - & 1 \\
\hline referência a questões sociais & 1 & - & - & - & 1 \\
\hline abordagem socio-cultural & 1 & - & - & - & 1 \\
\hline aulas mais prazerosas & 1 & - & - & - & 1 \\
\hline avaliação contínua & - & - & 1 & - & 1 \\
\hline método científico e redescoberta & - & - & - & 1 & 1 \\
\hline
\end{tabular}

Como se pode perceber nos dados da última coluna da tabela, os movimentos pedagógicos mais manifestados foram o ensino experimental e o lúdico, seguidos pelos temas interdisciplinaridade e educação ambiental. Esse fato leva a considerar que foram movimentos 
muito fortes no período em questão, pelo menos no âmbito da ação direta junto aos professores. De certa forma, a predominância de pelo menos dois desses temas (o ensino experimental e a educação ambiental) justifica-se pelo fato de serem metodologias associadas epistemologicamente às questões específicas do ensino de Ciências (Wortmann, 2003).

A recorrência de termos que remetem ao ensino lúdico, leva a refletir sobre a origem da necessidade de tornar as aulas mais prazerosas.

A partir da segunda metade do século XX, o ensino público no Brasil sofreu profundas mudanças filosóficas e abriu suas portas para uma nova clientela que, até então, não tinha acesso a ele. Quando a clientela majoritária da escola pública era composta por alunos oriundos da classe média, o ensino tradicional aparentemente dava conta das necessidades e dos anseios dessa classe. Havia uma pressão exercida pela família do estudante para que ele se saísse bem na escola, porque a família acreditava que só pela educação seu futuro estaria garantido. O aluno estudava e aprendia, em parte por força dessa cobrança que negociava até mesmo o presente de Natal como prêmio por ter "passado de ano" ou, por outro lado, ameaçava com castigos (muitas vezes físicos) o mau desempenho escolar. O prêmio ou o castigo, para alguns, parecia ser uma alavanca propulsora da necessidade de aprender.

Com o acesso das classes populares à escola pública, essa lógica parece deixar de existir (pelo menos com tanta unidade). Será que para essas famílias a escola não tem o mesmo valor que tinha para a classe média que a freqüentava antes? Se uma parcela desses novos "clientes" não estiver sujeita às mesmas motivações ou pressões que os anteriores, quais, então, poderiam ser as motivações para um bom desempenho escolar dos alunos? Se não são o medo, a obrigação, o prêmio ou o reconhecimento de uma possibilidade de ascensão social, é preciso haver um novo fator que sustente o interesse pela educação escolar, uma motivação para a permanência do estudante na escola.

Esse caminho de pensamento pode ter servido de base para justificar, pelo menos em parte, alguns movimentos presentes na educação nos últimos anos. Estabeleceu-se uma real necessidade de tornar a escola significativa do ponto de vista social para os alunos e, sob a significativa influência da psicologia, que promoveu a valorização da infância, foi preciso criar atrativos para manter as classes populares na escola. Assim, podem-se apontar alguns movimentos que contemplavam essa necessidade: a valorização de aspectos do cotidiano do aluno, do conhecimento significativo (em lugar daquele que se aprendia antes por que "um dia" poderia se precisar dele), a abertura de espaços na escola para valorizar aspectos da cultura local e a adoção de estratégias lúdicas (brincadeiras, jogos, representações teatrais etc.) como motivação do interesse do aluno, viabilizando a aprendizagem dos conteúdos curriculares.

Um pouco para corroborar esse pensamento, referindo-se ao modo como os sistemas educativos europeus se transformaram nos últimos vinte anos, Esteve (1995, p. 103) diz o seguinte:

Nos últimos vinte anos, a configuração do sistema educativo mudou radicalmente, passando de um ensino de elite, baseado na selecção e competência, para um ensino de massas, muito mais flexivel e integrador, mas incapaz de assegurar, em todas as etapas do sistema, um trabalho adequado ao nivel do aluno. Desta forma, desceu a motivação do aluno para estudar e a valorização social do sistema educativo. Enquanto que, há vinte anos, um grau acadêmico assegurava o "status" social e as compensações econômicas de acordo com o nivel obtido, hoje em 
Souza, L. H. P.; Gouvêa, G.

dia os graus acadêmicos não asseguram nada, mantendo-se outros mecanismos selectivos, que dependem das empresas privadas, das relações sociais da familia ou da obtenção de conhecimentos extracurriculares que não fazem parte do sistema regular de ensino (idiomas, informática etc.).

[...] É absurdo manter num ensino massificado os objectivos traçados para um ensino de elite, o que conduziu os sistemas de ensino a uma maior diversificaşão e flexibilidade; em termos de rendibilidade social não podemos esperar resultados idênticos aos que eram obtidos pelos antigos sistemas, que serviam uma elite tanto mais restrita quanto mais se avançava nos diversos escalões da hierarquia escolar. (Ranjard, 1984, p.103-104)

Apesar de o autor referir-se à realidade européia, é inegável a semelhança com as questões brasileiras. Assim, quando o assunto é a desvalorização da educação por parte da própria população deve-se considerar que, de certa forma, a massificação da escolaridade decepcionou essa parcela menos favorecida, na medida em que não produziu a igualdade nem a promoção social esperadas (Ranjard, 1984).

\section{Referências}

AMARAL, I. A. Oficinas de produção em ensino de Ciências: uma proposta metodológica de formação continuada de professores. In: TIBALLI, E. F. A.; CHAVES, S. M. (Orgs.). Concepções e práticas em formação de professores: diferentes olhares. Rio de Janeiro: DP\&A, 2003. p. 147-164.

BAKHTIN, M. M. (VOLOCHINOV). Marxismo e filosofia da linguagem. São Paulo: Editora Hucitec, 1986.

CHRISTOV, L. H. S. Educação continuada: função essencial do coordenador pedagógico. In: GUIMARÃES, A. A.; MATE, C. H.; BRUNO, E. B. G.; VILELA, F. C. B.; ALMEIDA, L. R.; CHRISTOV, L. H. S.; SARMENTO, M. L. M.; PLACCO, V. M. N. S. O coordenador pedagógico e a educação continuada. São Paulo: Loyola, 1998.

COPELLO LEVY, M. I.; SANMARTÍ PUIG, N. Fundamentos de un modelo de formación permanente del professorado de Ciências centrado en la reflexión dialógica sobre las concepciones y las práticas. Enseñanza de las Ciencias, v. 19, n. 2, p. 269-283, 2001.

ESTEVE, J. M. Mudanças sociais e função docente. In: NÓVOA, A. (Org.). Profissão professor. Porto: Porto Editora LDA, 1995. p. 93-124. 
Oficinas pedagógicas de Ciências: os movimentos...

GIL-PÉREZ, D. Formação de professores de ciências: tendências e inovações. Trad: Sandra Valenzuela. 7. ed. São Paulo: Cortez, 2003. (Coleção Questões da nossa época, v. 26).

KRASILCHIK, M. O professor e o currículo das ciências. São Paulo: EPU, 1987.

MARANDINO, M. O ensino de Ciências e a perspectiva da didática crítica. Rio de Janeiro, 1994. Dissertação (Mestrado em Educação) - Faculdade de Educação, PUC/RJ.

MINAYO, M. C. S. O desafio do conhecimento: pesquisa qualitativa em saúde. 7.ed. Rio de Janeiro: Abrasco, 2000.

NÓVOA, A. Os professores na virada no milênio: do excesso dos discursos à pobreza daspráticas. Revista Educação e Pesquisa, v. 25, n. 1, p. 11-20, 1999.

PORLÁN, R.; RIVERO, A. El conocimiento de los profesores: el caso de la enseñanza de las Ciencias. Sevilha: Diada, 1998. (Série Fundamentos n. 9)

PIMENTA, S. G. Formação de professores: identidade e saberes da docência. In: PIMENTA, S. G. (Org.). Saberes pedagógicos e atividade docente. São Paulo: Cortez, 1999. p. 15-33.

RANJARD, P. Les enseignants persècutès. Paris: Robert Jauze, 1984.

SELLES, S. E. Formação continuada e desenvolvimento profissional de professores de Ciências. Revista Ensaio, v. 2, n. 2, 209-229, 2000.

WORTMANN, M.L.C. Currículo e Ciências - as especificidades do ensino de Ciências. In: COSTA, M. V. (Org.). O currículo nos limiares do contemporâneo. 3. ed. Rio de Janeiro: DP\&A, 2003. p. 129-157.

VIANA, D. M.; CARVALHO, A. M. P. Formação permanente: a necessidade da interação entre a ciência dos cientistas e a ciência da sala de aula. Ciência $\boldsymbol{\&}$ Educação, v. 6, n. 1, p.3142, 2000.

Artigo recebido em fevereiro de 2006 e aceito em setembro de 2006 